\title{
A Comparative Analysis on the Psychological Wellbeing of Adolescents with Parents in the Diaspora and those with Parents in the Home Country: A Case Study of Adolescents at Nemakonde High School, Mashonaland West Region, Zimbabwe
}

\author{
Pamela Chakombera $^{1^{*}}$, Augustine K. Mubika ${ }^{2}$ \\ ${ }^{l}$ Midlands State University BSc Psychology Honours graduate, Zimbabwe \\ ${ }^{2}$ Senior Lecturer: Zimbabwe Open University: Faculty of Arts and Education, Zimbabwe
}

*Corresponding Author: Pamela Chakombera, Midlands State University BSc Psychology Honours graduate, Zimbabwe

\begin{abstract}
The absence of parents as a cause of migration has had negative implications on the psychological wellbeing of the adolescents left behind. This study sought to find if there are any significant differences in the psychological wellbeing for adolescents with parents in the diaspora and adolescents with parents in the home country. The study adopted the quantitative research paradigm, and used the descriptive survey design. Quantitative paradigm is considered efficient and can test hypothesis thus the researchers found it suitable as it suits the objectives of the study. The research drew a sample of 202 participants of which 50\%(101) had parents in the diaspora and another 50\%(101) had parents in the home country. Both the stratified random sampling and the random sampling techniques were used. Data were analysed using both inferential and descriptive statistics. These were used to analyse the data and present findings. The findings of the research suggest that there are significant differences in the psychological well-being of adolescents with parents the diaspora and those with parents with in the home country. The descriptive survey design was chosen because it provides frequencies and distributions of experiences in a manner that readers can easily comprehend. There is need for more research studies as there is a dearth in the literature regarding migration and generally, left behind families in Zimbabwe.
\end{abstract}

\section{BACKGROUND TO THE STUDY}

External migration also known as international migration is very common in developing countries worldwide where citizens leave their home countries to go to other countries. In most cases parents leave their children behind due to many factors for instance some migrants enter the receiving country illegally and taking children along can be risky, there may be difficulties in receiving countries, temporary migration, unfavorable immigration policies in the receiving countries among others (Bălţătescu, Hatos \& Oșvat, 2014). Out migration is considered voluntary or involuntary on the parent's side. According to Flahaux and De Haas (2016), the African continent is regarded to be with the most mobile populaces in the world, it is stereotyped to be a continent on the move. Out-migration is also prominent in the Caribbean islands of America in countries like Guyana, Haiti, and Jamaica among other countries. Most studies have been carried out in these countries on the effects of migration on children as well as families left behind. Crawford-Brown (1994) in a study in Jamaica coined the word 'barrel children' to refer to Jamaican children deprived of their parents and are products of what is termed 'stepwise migration'.

Out-migration of this nature is due to several factors which include socio-economic challenges, job searches and better learning conditions. The adoption of the United States dollar by Zimbabwe government in 2009 has not done much to eradicate the socio-economic challenges that are prominent in the country of study, Zimbabwe. Thus, the number of people migrating from Zimbabwe has not decreased. Zimbabwe's economic empowerment policies do not attract foreign investments, and this has resulted in the dilapidation of the country's economy resulting in national unemployment. Studies on the effects of parental international migration on adolescents have been carried out in Beitbridge and Shashe; southern part of Zimbabwe. 
A Comparative Analysis on the Psychological Wellbeing of Adolescents with Parents in the Diaspora and those with Parents in the Home Country: A Case Study of Adolescents at Nemakonde High School, Mashonaland West Region, Zimbabwe

Adolescents might find it difficult to cope with the transitions that come along with this stage of life. This age group is distinct in its own ways. Adolescents need the psychological help of parents and others to cope with the various changes that occur at this stage of life. Given this it becomes apparently clear that in the absence of parents, problems affecting the adolescents left behind by their parents would negatively affect the adolescents' psychological wellbeing.

\section{Statement of The Problem}

The rate of international migration has increased in the recent years. In recent years, there hasan increase in the rate of emigration of the Zimbabwean citizens. These migrants leave their children behind voluntarily or involuntarily. The absence of parents has created serious psychological problems on the adolescents left behind. This has created a margin between adolescents with parents in the home country and those with parents in the diaspora. Given all this, the researchers have found it necessary to consider whether there are differences in the psychological wellbeing between adolescents with parents find out if there are any significant differences in the psychological wellbeing for adolescents with parents in the diaspora and those with parents in the home country with reference to Nemakonde High School, Chinhoyi, Mashonaland West Province in Zimbabwe.

\section{RESEARCH QUESTIONS}

To respond to the main research problem, this study attempted to answer the following research subproblems which stand as research questions:

1. Are there any significant differences in autonomy for adolescents with parents in the diaspora and those with parents in the home country?

2. Are there any significant differences in environmental mastery for adolescents with parents in the diaspora and those with parents in the home country?

3. Are there any significant differences in personal growth for adolescents with parents in the diaspora and those with parents in the home country?

4. Are there any significant differences in positive relations for adolescents with parents in the diaspora and those with parents in the home country?

5. Are there any significant differences in purpose for life for adolescents with parents in the diaspora and those with parents in the home country?

6. Are there any significant differences in self- acceptance for adolescents with parents in the diaspora and those with parents in the home country?

\section{Significance OF THE STUdY}

The study is likely to help adolescents develop an understanding that absence of parents at times is not by choice and as such they should not live their lives blaming their parents for every experience they encounter. The study is likely to provide adolescents with a platform to self-evaluate and appreciate absence of parents as a measure central to personal growth and use of independence responsibly;it is the foundation to the development of individual maturity. This research is likely to help parents understand the importance of their presence in the children's lives and how it interacts with adolescents' emotional, psychological, social and behavioral development. The research is likely to help parents appreciate that frequent contact with children is significant for esteem, confidence, selfworth and efficacy of adolescents. The study is likely to develop a platform for further research into psychological experiences of adolescents with parents who live in the diaspora. The research will also add to the board of literature on the experiences of adolescents as well as strategies to enhance their psychological well-being.

\section{REVIEW OF RELATED LITERATURE}

\subsection{International Migration}

This refers to the movement of people from one country to other countries, in search of opportunities to better their lives, seek political refugee, further one's studies, gain new experiences, and flee from disaster and famines among others. This is a political, economic as well as a social process that has an 
A Comparative Analysis on the Psychological Wellbeing of Adolescents with Parents in the Diaspora and those with Parents in the Home Country: A Case Study of Adolescents at Nemakonde High School, Mashonaland West Region, Zimbabwe

impact on the source and receiving countries. Globalization has contributed to the rise of migration in the world as people worldwide can now easily connect.

Zimbabwe National Statistics Agency (ZIMSTAT) in 2014 asserts that $43.9 \%$ of Zimbabweans emigrated due to the lack of job opportunities, whilst $18.3 \%$ migrated in the questto increase household income. Illegal migration is very common in Zimbabwe and in most cases the migrants would be migrating to countries in southern Africa. The organization ZIMSTAT (2014) posits that $85.7 \%$ of Zimbabwean emigrants would be migrating to South Africa and among them are illegal migrants. Dube (2014) in a study in the southern part of Zimbabwe found that most of these illegal emigrants leave children behind because they consider the process of illegal migration dangerous and they cannot risk their children's lives. According to ZIMSTAT(2014) the organization revealed that $53 \%$ of out-going, $41.9 \%$ labour migrants had left children, adolescents included, behind in the home country Zimbabwe.

Africa has been tagged one of the world's regions with the highest migrating populaces and this has been mainly attributed to socio-economic challenges and political instability among others. Africans in East and North Africa usually migrate to countries in Europe. In most instances the Africans migrate to nations that once colonized them. The Caribbean islands of America, South America, India and China are some of the regions in the world with high levels of emigration.

International migration poses certain problems to both the receiving and sending nations.

\subsection{Parental Absence and Psychological Wellbeing of the Adolescents Left Behind}

Ryff (1989) asserts that psychological well-being generally refers to positive mental health. Ryff, (1989) further stipulates that psychological wellbeing is a diverse and multidimensional concept. Psychological well-being can be defined as how adolescents evaluate themselves and their ability to accomplish aspects of their life. Ryff and Keyes (1995) assert that objective psychological well-being consists of the six domains namely: autonomy, environmental mastery, personal growth, positive relations, purpose in life and self-acceptance. Parental absence that results from migration has negative implications on the psychological well-being of the adolescents left behind. Serantna (2007) findings in a study in the Colombo district in Sri Lanka suggests that children left behind by migrant mothers have a poor psychological wellbeing.

\subsection{Differences in Autonomy for Adolescents with Parents in the Diaspora and those with Parents in the Home Country}

Erickson (1963) defines autonomy as an adolescent's sense of freedom. Ryff and Keyes (1995) assert that autonomy is the regulation of an individual's behavior and this is coming from within the individual. A fully functioning adolescent should be able to evaluate themselves with the use of their own standards and not using other people's standards. Dube (2014) offer suggestive evidence that adolescents left behind by migrant parents develop a sense of freedom earlier than adolescents with parents in the home country. Dube (2014) reported that teachers in Zimbabwe stated that adolescents who are left to head families are difficult to govern. This is attributed to the fact that they would be regarding themselves as adults since they partake in parental roles and duties. Autonomy is associated with high levels of motivation. Dube (2014) asserts that adolescents are motivated to work hard so that they can be able to migrate to where their parents are.

\subsection{Differences in Environmental Mastery for Adolescents with Parents in the Diaspora and those in the Home Country}

Ryff and Keyes (1995) posit that environmental mastery is another element of psychological wellbeing. Adolescents with high levels of psychological wellbeing are competent and can adapt to different situations. They often make the best out of any situation they are presented. Attention deficit is common in the adolescents left behind by migrant parents; they fail to focus on real moments as they tend to escape from reality putting their focus on the imaginary world with the migrant parent, responsibilities they are taking over, remittances, gifts and the like. Jones, Sharpe and Sogren(2004) assert that children left behind by migrant parents are often distressed. Toth, Toth, Voicu and Stefanescu (2007) posit that these children often find it hard to cope with the day to day activities they face. 
A Comparative Analysis on the Psychological Wellbeing of Adolescents with Parents in the Diaspora and those with Parents in the Home Country: A Case Study of Adolescents at Nemakonde High School, Mashonaland West Region, Zimbabwe

\subsection{Differences in Personal Growth for Adolescents with Parents in the Diaspora and those with Parents in the Home Country}

Ryff and Keyes (1995) posit that personal growth is the capability to develop the self, to self-actualize and to mature to be a fully functioning person. Adolescents with a high psychological wellbeing have a sense of development within themselves. Parental absence due to migration can result in adolescents lacking that sense of development. Nana (2008) posits that female adolescents left behind by their mothers are subject to sexual abuse and incest. It is reported that they are considered a substitute of their mothers and are often abused by their father and close relatives. It is reported that $50 \%$ of incest cases in Sri Lanka where attributed to the absence of a maternal figure on the adolescent's part. This has a negative impact on the adolescent's personal development. In most cases these girls lose hope in life and do not have any goals they intend to achieve. Adolescents left behind lack significant roles models in the form of parents. These role models ensure that they value education. The absence of a parental figure deprives the adolescents of the benefits of having a role model. This encourages the adolescent's lack of responsibility, engage in delinquent behaviours and lack of interest in academic work (Spera, 2005).

\subsection{Difference in Positive Relations for Adolescents with Parents in the Diaspora and those with Parents in the Home Country}

Ryff (1989) posits that good relations often results in one understanding others, bad relations on the other hand results in frustration. Children left behind are often characterized by disorderliness and rebellious this is attributed to the absence of male role models in their lives (Toth et al, 2007).According to Toth et al (2007), the absence of one or both parents' results in the deterioration of the parent and child relationship. They further report that there is a high percentage of children who do not have good relations with their mothers in the case that their fathers are abroad, it is even more visible to children living with their fathers. Toth et al (2007)asserts that children with both parents in the diaspora have better communication or relations with peers, friends and relatives as compared with children living with both parents. Jones, Sharpe and Sogren (2004) assert that children left behind often have difficulties in developing healthy relationships.

\subsection{Differences in Purpose in Life for Adolescents with Parents in the Diaspora and those with Parents in the Home Country}

Ryff and Keyes (1995) posit that purpose in life is the perceived significance of an individual by oneself; it mainly has to do with goal setting and achievement of set goals. It also involves the appreciation of life. High scores in terms of purpose in life are indicated by an adolescent's sense of direction in life, happiness and love among others. Low scores in terms of purpose in life are indicated by the adolescents' lack of goals and aims in life, sadness among others. In most cases Zimbabwean migrant mothers in South Africa return with newborn children and in most cases, these would have been conceived abroad (Dube, 2014). These children are in some cases labeled 'bastard' children and they grow up with this stigma which usually negatively affects them. Stigmatization mainly comes from relatives, the community in which the children live in, school peers and teachers. This then results in the adolescents lacking interest in life, in some cases this leads to the adolescents committing suicide (Nana, 2008).Dube (2014) postulates that adolescents left behind by migrant parents lack long term goals in life. Cortes (2008) studies in Moldova offer suggestive evidence that the increase in crime rate in the nation between the years 1993-2000 is positively correlated to a rise in barrel adolescents.

According to Crawford-Brown (1994), parents in the diaspora send in gifts to compensate the separation with their adolescents, making them more attached to material goods. This has resulted in a loss of moral values and decline in the love and respect for the migrant parents. It was also noted that the quest for material objects lead adolescents to crime and violence. Adolescents engaging in such behaviors can be an indication of lack of clear aims in one's life. The (UNICEF, 2011) in a study in Tajikistan concluded that adolescents with parents in the diaspora were more likely to commit juvenile crime as compared to adolescents with parents in the home country. This then has effects on their score in the domain of purpose in life. 
A Comparative Analysis on the Psychological Wellbeing of Adolescents with Parents in the Diaspora and those with Parents in the Home Country: A Case Study of Adolescents at Nemakonde High School, Mashonaland West Region, Zimbabwe

\subsection{Differences in Self-Acceptance for Adolescents with Parents in the Diaspora and those with Parents in the Home Country}

Self-acceptance is another element of psychological wellbeing (Ryff\& Keyes, 1995). They further assert that a high score on self-acceptance is characterized by a positive attitude towards oneself. A low score is characterized by dissatisfaction about oneself among others. According to Dube (2014) children left behind experience self-esteem disorders, they tend to over appreciate their peers and under appreciate themselves in the cases that other children have parents that are involved in their peer's lives, for example, parents that share their time with their children. Jones, Sharpe and Sogren(2004)posit that children, who experience shifting from one home to the other exhibit low levels of self-efficacy and in most cases, are always sad. They further postulate that the adolescents are usually distressed. The adolescents can feel abandoned, sad, and anxious, have episodes of depression and these are a cause of the separation of them from their parents (Bălţătescu, Hatos\&Oșvat, 2014).The adolescents' lack their parent's affection and often no one gets to appreciate them, and this often leads to depression in the adolescents. A study carried out by Bălţătescu et al (2014), in Berlin, Romania, suggests that adolescents with parents in the home country where happy as compared to adolescents with parents in the diaspora. Zhao et al. (2012) offer suggestive evidence that parental migration in Ningxia Province resulted in a decrease in adolescent's self-esteem and this is attributed to the absence of the parents.

\section{THEORETICAL FRAMEWORK}

\subsection{Attachment Theory}

John Bowlby's attachment theory suggests that all humans do have an innate instinct that implores protection and care. He posits that parents are sensitive and more responsive to their children and allow them to grow in a healthy way. Bowlby (1989) further states that parents who are the opposite of allow the children to grow in an unhealthy manner resulting in deviant behaviors. This in turn makes them vulnerable in the case that they face adverse situations. According to the International Organization of Migration findings in Bangladesh, it was revealed that male adolescents left behind in the care of their mothers lacked discipline and were often rebellious. In most cases these adolescents viewed themselves as independent and often indulged in socially unacceptable behaviors. Adolescents left in child headed homes without adult supervision are often absent at school and this results low pass rates (Dube 2014). Bowlby (1989) suggests that lengthy separation of a child from the parent in the early years of the child's life has an impact on the child's personality. It is clinically proven that such children are normally isolated and often withdraw from other peers (Bowlby, 1973). Some of the psychological problems associated with the separation are suicidal tendencies, personality disorders, depression among others. This normally occurs when the substitute of the parental figure cannot deal with the child effectively. Migration can result in maternal deprivation on the adolescents left behind. Bowlby(1940)quoted by Caspers, Cadoret, Langbehn, Yucuis and Troutman (2005) posits that maternal deprivation results in negative implications; some of them are aggression, anxiety of being left alone, being affectionless, depression and manifestation of delinquent behaviors among others.

\section{RESEARCH METHODOLOGY}

The study adopted the quantitative research approach and the descriptive survey design was chosen. Thus, the researchers considered two groups of participants, adolescents with parents in the diaspora and adolescents with parents in the home country. This involved counting the participants and constructing statistical models that sought to explain the effects of parental international migration on the psychological wellbeing of adolescents and to see if there are any significant differences between the two groups. Quantitative data is considered efficient and can test hypothesis thus the researchers found it suitable as it suits the objectives of the study. Quantitative research facilitates objectivity rather than subjectivity and this ensures reliability of the end results. Quantitative research is also considered deductive in nature and this suits well with the research as it is deductive when it tests for the research hypothesis. Quantitative research guarantees the generalisability and representativeness of a given population hence the researchers used this approach. Given the above the researchers sought to depict participants in a more accurate manner using the descriptive survey research design. This design was used because it provides an insight into the magnitude of experiences of 
A Comparative Analysis on the Psychological Wellbeing of Adolescents with Parents in the Diaspora and those with Parents in the Home Country: A Case Study of Adolescents at Nemakonde High School, Mashonaland West Region, Zimbabwe

psychological experiences of the participants. The descriptive survey design provides frequencies and distribution of experiences in a manner that readers can understand easily and make sense of the data that have been provided for.

\section{TARGET POPUlation}

The target population of the study constitutes of Nemakonde High School's 400 students (Makonde District, Mashonaland West Province: Zimbabwe) from form one to four with all the participants not discriminated against. The population is made up of students with parents in the diaspora and those with parents in the home country.

\section{SAMple ANd SAMpling Procedure}

The researcher drew a sample of 202 individuals with guidance of the Shakaran table for determining sample sizes. $101(50 \%$ of the sample) adolescents had parents in the home country and these represented the control group. The other 101(50\% of the sample) adolescents had parents in the diaspora and these represented the experimental group. The sample size was drawn at confidence level $95 \%$ and a degree of accuracy 0.05 . The researchers used stratified random sampling to gather participants for the study. Through stratified random sampling, the researchers put the participants into clusters based on the form, residence of the child's parents, and gender of the student and based on age of the student (13-18years).

\section{DATA COLLECTION INSTRUMENTS}

The researchers used the questionnaire as the main research data collection instrument, and this was used to collect data that relate to the research objectives. The researchers appropriately adapted Carol Ryff's (1995) psychological wellbeing scale with 44 items. This instrument measured the adolescent's psychological wellbeing. The reliability co-efficient of the six subscales (autonomy, environmental mastery, personal growth, positive relations, purpose in life and self-acceptance) is above .70 . The respondents indicated their level of agreement or disagreement to the provided questions on the questionnaire. The researchers chose the questionnaire for it best suits quantitative research and it is objective in nature ensuring reliability of the test results. All sections contained questions on a five unidirectional Likert scale. The respondents indicated their level of agreement or disagreement to the provided questions on the questionnaire. The researchers had also earlier on conducted a feasibility study on 40 high school students at King Solomon College in Chinhoyi with similar characteristics to those of the intended population. This was to see if the questionnaire designed and the sub sections on it were clear to the participants. The pre-testing procedure was also an approximate of the original research methodology to assess the validity and reliability of the approach to research. The researchers from this pre-test identified that the Cronbach alpha of the instrument was slightly high ranking at significant level .784 , and this signified that the instrument was reliable and valid in assessing what it was intended to measure. The data collected in the research was analyzed using the Statistical Package for the Social Sciences (SPSS) version 16.1. Data collected in the field was assessed using a wide range of statistical procedures. Both inferential and descriptive statistics where used to analyze and present the findings. The data was analyzed using T-Test that tested for significant differences between the two populations that where being assessed for their psychological experiences and how they affect the wellbeing of these students. To further justify our t-test a pretest was carried out and data was drawn from a normally distributed population and interval data was used in the study. The t-test was chosen as it tests for differences between two independent samples.

\section{Presentation of Data}

Table1 below shows that there were significant differences between and within psychological wellbeing amongst adolescents whose parents are in the diaspora and those with parents in the home country. This was signified by a .000 significant level drawn from the t Test in terms of autonomy, environmental mastery, personal growth, positive relations, and purpose life, self-acceptance and therefore, the overall psychological wellbeing. It then follows that parental presence and/or absence has significant influence on the psychological wellbeing of adolescents as indicated by the results. 
A Comparative Analysis on the Psychological Wellbeing of Adolescents with Parents in the Diaspora and those with Parents in the Home Country: A Case Study of Adolescents at Nemakonde High School, Mashonaland West Region, Zimbabwe

\section{Independent Samples Test}

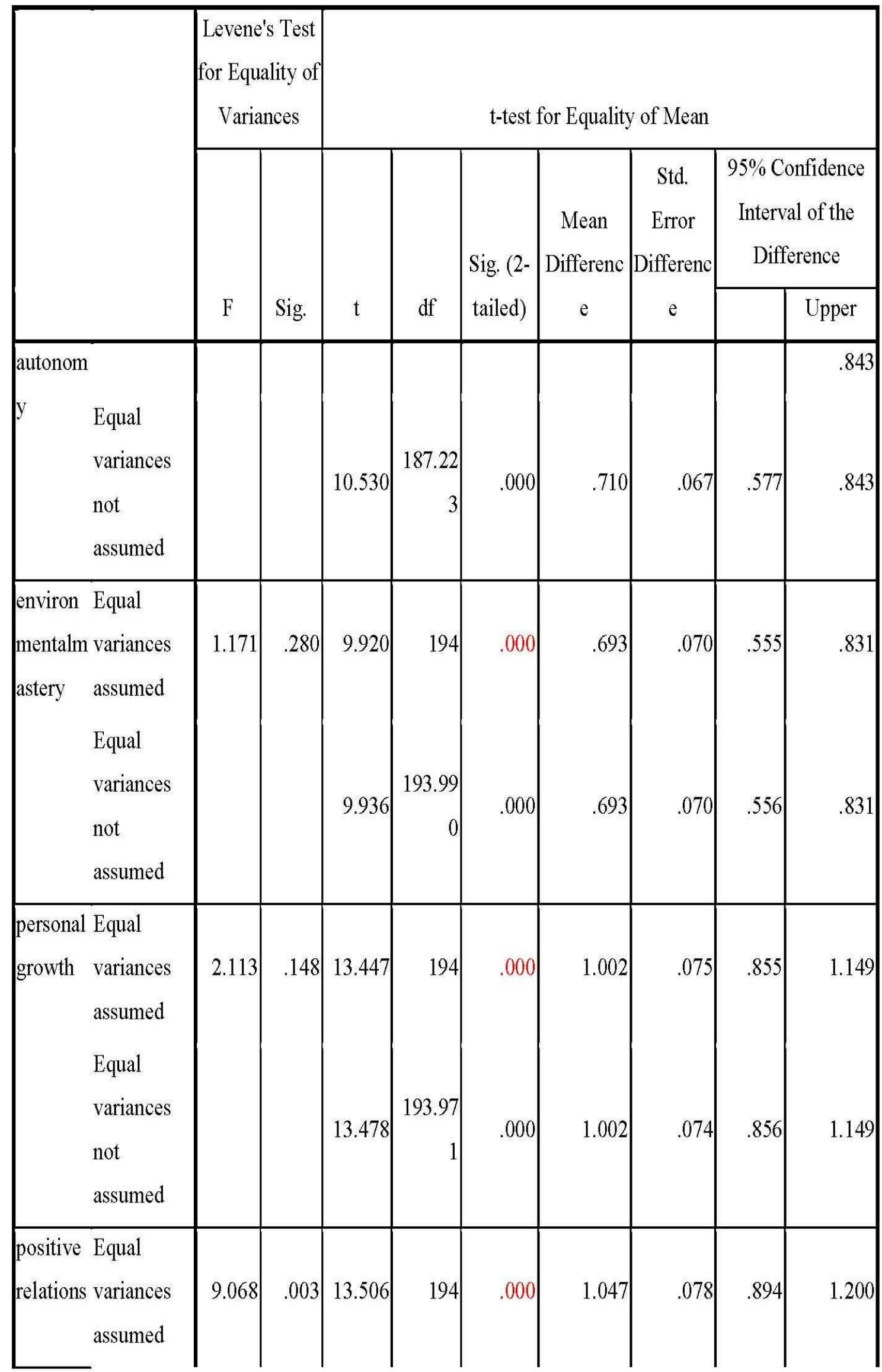


A Comparative Analysis on the Psychological Wellbeing of Adolescents with Parents in the Diaspora and those with Parents in the Home Country: A Case Study of Adolescents at Nemakonde High School, Mashonaland West Region, Zimbabwe

\begin{tabular}{|c|c|c|c|c|c|c|c|c|c|c|}
\hline & $\begin{array}{l}\text { Equal } \\
\text { variances } \\
\text { not } \\
\text { assumed }\end{array}$ & & & 13.584 & $\begin{array}{r}190.97 \\
1\end{array}$ & .000 & 1.047 & .077 & .895 & 1.199 \\
\hline $\begin{array}{l}\text { purpose } \\
\text { in life }\end{array}$ & $\begin{array}{l}\text { Equal } \\
\text { variances } \\
\text { assumed } \\
\text { Equal } \\
\text { variances } \\
\text { not } \\
\text { assumed }\end{array}$ & 11.117 & .001 & 11.344 & $\begin{array}{r}194 \\
\\
190.99 \\
2\end{array}$ & .000 & .799 & .070 & .660 & .938 \\
\hline $\begin{array}{l}\text { self- } \\
\text { acceptan } \\
\text { ce }\end{array}$ & $\begin{array}{l}\text { Equal } \\
\text { variances } \\
\text { assumed } \\
\text { Equal } \\
\text { variances } \\
\text { not } \\
\text { assumed }\end{array}$ & .048 & .826 & 11.157 & $\begin{array}{r}194 \\
\\
192.58 \\
3\end{array}$ & .000 & .848 & .076 & .698 & .998 \\
\hline $\begin{array}{l}\text { psychol } \\
\text { ogical } \\
\text { welbein } \\
\text { g }\end{array}$ & $\begin{array}{l}\text { Equal } \\
\text { variances } \\
\text { assumed } \\
\text { Equal } \\
\text { variances } \\
\text { not } \\
\text { assumed }\end{array}$ & 94.332 & .000 & 11.324 & 194 & .000 & 679 & .060 & .561 & .799 \\
\hline
\end{tabular}

\section{DisCUSSION OF RESUlTS}

The results of the study indicate that there are significant differences in autonomy for adolescents with parents in the diaspora and adolescents with parents in the home country. This is confirmed by Dube(2014) who asserts that adolescents left behind by migrant parents in Zimbabwe develop a sense of independence earlier than adolescents with parents in the home country. The study also suggests that there are significant differences in terms of environmental mastery between the two groups under study. The Soros Foundation Romania supports this when he posits that adolescents with parents abroad fail to focus on the present live in the present and this then affects their psychological wellbeing in terms of environmental mastery. There are significant differences in terms of personal growth between the two groups. Spera (2005) asserts that adolescents that lack role models in the form of parent's lack life time aspirations thus resulting in the difference in terms of personal growth between the two groups. The study results also show that there are significant differences in positive relations for adolescents with parents in the diaspora and those in the home country. Peterson and Zill (1986) findings support this when they suggest that adolescents who are attached to their fathers and spend much time with them are sociable and often less affected by depression, their relations are positive. The study also indicates that there are significant differences in terms of purpose in life between the two groups. Hence, Bălțătescu et al (2014) support this when they say that adolescents 
A Comparative Analysis on the Psychological Wellbeing of Adolescents with Parents in the Diaspora and those with Parents in the Home Country: A Case Study of Adolescents at Nemakonde High School, Mashonaland West Region, Zimbabwe

with parents in the home country are happier as compared to adolescents with parents abroad. Adolescents with high scores of psychological wellbeing are self-accepting. Dube (2014) agrees with when he asserts that adolescents with parents abroad often over and under appreciate their peers and in most cases, have a low self-esteem. This then explains the differences between the two groups. The study shows that adolescents with parents in the home country have a better psychological wellbeing as compared to adolescents with parents abroad. This then shows the applicability of John Bowby's attachment theory in that parent-child separation has negative implications on the child psychological wellbeing. Mazzucato, Cebotari, Veale, White, Grassi and Vivet (2015) in a study involving Ghana, Nigeria and Angola concluded that children left behind by migrant parents suffer psychologically. Graham and Graham and Jordan (2011) in a study in Indonesia concluded that there was a significant difference in psychological wellbeing for children including adolescents who were living in transnational households as compared to children living with parents in the home country.

\section{CONClusions}

From the above discussions, the following conclusions were made:

1. There are significant differences in autonomy for adolescents with parents in the diaspora and those with parents in the home country.

2. There are significant differences in environmental mastery for adolescent's parents in the diaspora and those with parents in the home country.

3. There are significant differences in personal growth for adolescents with parents in the diaspora and those with parents in the home country.

4. There are significant differences in positive relations for adolescents with parents in the diaspora and those with parents in the home country.

5. There are significant differences in purpose of life for adolescents with parents in the diaspora and those with parents in the home country.

6. There are significant differences in self-acceptance for adolescents with parents in the diaspora and those with parents in the home country.

Finally, this study concludes that there are significant differences in the psychological wellbeing for adolescents with parents in diaspora and those with parents in the home country. The research findings indicate poor psychological wellbeing on adolescents with parents abroad (diaspora) as compared to adolescents with parents in the home country.

\section{RECOMMENDATIONS}

1. The study recommends that Ministry of Primary and Secondary Education facilitate counseling and guidance to the adolescents left behind as well as the guardians left with the adolescents.

2. It is also recommended that the Ministry, referred to above, come up with a wide range of psychological interventions that can be implemented to deal with the psychological effects of parental migration on the wellbeing of the adolescents left behind.

3. There is dearth in research on migration and left behind children as well as families also left behind. Apart from the aspects of psychological wellbeing addressed in this study there is need for the other aspects of wellbeing to be researched on.

\section{REFERENCES}

[1] Bălţătescu, S., Hatos, A., \&Oșvat, C. The effects of parental migration on subjective well-being of children: The case of Romania.

[2] Bowlby, J., May, D. S., \& Solomon, M. (1989). Attachment Theory. Lifespan Learning Institute.

[3] Bowlby, J. (1973). Attachment and loss: Separation (vol. 2).

[4] Caspers, K. M., Cadoret, R. J., Langbehn, D., Yucuis, R., \& Troutman, B. (2005). Contributions of attachment style and perceived social support to lifetime use of illicit substances. Addictive Behaviors, 30(5), 1007-1011. 
A Comparative Analysis on the Psychological Wellbeing of Adolescents with Parents in the Diaspora and those with Parents in the Home Country: A Case Study of Adolescents at Nemakonde High School, Mashonaland West Region, Zimbabwe

[5] Cortes, R. (2008). Children and Women Left Behind in labour sending countries: An Appraisal of social risks. New York: United Nations Children's Fund (UNICEF), Policy, Advocacy and Knowledge Management Section, Division of Policy and Practice.

[6] Crawford-Brown, C. (1994). The "Barrel Children" of the Caribbean: The Socio-cultural Context of the Migrant Caribbean Family. Dept. of Sociology and Social Work, UWI, Mona, Jamaica ISER

[7] Dube, T. (2014). The Socio-Economic Effects of Cross-Border Migration on Zimbabwe's Border Lying Communities-A Case Study of Beitbridge and Plumtree.

[8] Erikson, E. H. (1963). Childhood and society (Rev. ed.).

[9] Flahaux and De Haas Comparative Migration Studies (2016) 4:1 DOI 10.1186/s40878-015- 0015-6

[10] Graham, E., \& Jordan, L. P. (2011). Migrant parents and the psychological well- being of left- behind children in Southeast Asia. Journal of Marriage and Family, 73(4), 763-787.

[11] Jones, A., Sharpe, J., \&Sogren, M. (2004). Children's experiences of separation from parents as a consequence of migration. Caribbean Journal of Social Work, 3(1), 89-109.

[12] Mazzucato, V., Cebotari, V., Veale, A., White, A., Grassi, M., \&Vivet, J. (2015). International parental migration and the psychological well-being of children in Ghana, Nigeria, and Angola. Social Science \& Medicine, 132, 215-224.

[13] Nana, O. (2008). Family without borders? Asian women in migration and the transformation of family life. Asian Journal of Women's Studies, 14(4), 54-79.

[14] Peterson, J. L., \&Zill, N. (1986). Marital disruption, parent-child relationships, and behavior problems in children. Journal of Marriage and the Family, 295-307.

[15] Ryff, C. D. (1989). Happiness is everything, or is it? Explorations on the meaning of psychological wellbeing. Journal of personality and social psychology, 57(6), 1069.

[16] Ryff, C. D., \& Keyes, C. L. M. (1995). The structure of psychological well-being revisited. Journal of Personality and Social Psychology, 69(4), 719.

[17] Spera, C. (2005). A review of the relationship among parenting practices, parenting styles, and adolescent school achievement. Educational Psychology Review, 17(2), 125-146.

[18] Toth, G., Toth, A., Voicu, O., \&Stefanescu, M. (2007). The Effects of Migration: Children Left Behind. Soros Foundation Romania.

[19] UNICEF (2011). Impact of labour migration on "children left behind" in Tajikistan. UNICEF Publication: Dushanbe, Tajikistan.

[20] Zhao, Miaomiao, Hui Li, Jun Li, Guilin Li, Cuili Wang, Stephen Nicholas and Qinyue Meng, (2012). "Studying on the influence of migrant parents on mental health of their left-behind children in rural China," ZhongguoWeishengShiyeGuanli (The Chinese Health Service Management), Vol. 283, No. 1, pp. 60-63.

[21] Zimbabwe National Statistics(ZIMSTAT) (2014). Multiple Indicator Cluster Survey 2014, Key Findings. ZIMSTAT, Harare, Zimbabwe. URL: http://www.childinfo.org/files/Zimbabwe_2014_KFR.pdf

Citation: Pamela Chakombera, Augustine K. Mubika. "A Comparative Analysis on the Psychological Wellbeing of Adolescents with Parents in the Diaspora and those with Parents in the Home Country: A Case Study of Adolescents at Nemakonde High School, Mashonaland West Region, Zimbabwe." International Journal of Humanities Social Sciences and Education (IJHSSE), vol 5, no. 2, 2018, pp. 17-26. doi: http://dx.doi.org/10.20431/2349-0381.0502003.

Copyright: (C) 2018 Authors. This is an open-access article distributed under the terms of the Creative Commons Attribution License, which permits unrestricted use, distribution, and reproduction in any medium, provided the original author and source are credited. 